\title{
Capitalismo e monopólio de conhecimento
}

Capitalism and Knowledge Monopoly

Capitalisme et monopole de la connaissance

José Arthur Giannotti

\section{OpenEdition}

\section{Journals}

Edição electrónica

URL: http://journals.openedition.org/rccs/1283

DOI: $10.4000 /$ rccs. 1283

ISSN: 2182-7435

\section{Editora}

Centro de Estudos Sociais da Universidade de Coimbra

Edição impressa

Data de publição: 1 Outubro 2002

Paginação: 211-235

ISSN: 0254-1106

Refêrencia eletrónica

José Arthur Giannotti, "Capitalismo e monopólio de conhecimento », Revista Crítica de Ciências Sociais [Online], 63 | 2002, colocado online no dia 01 outubro 2012, criado a 19 abril 2019. URL : http:// journals.openedition.org/rccs/1283; DOI : 10.4000/rccs.1283 


\section{JOSÉ ARTHUR GIANNOTTI}

CEBRAP - Centro Brasileiro de Análise e Planejamento e Universidade de São Paulo

\section{Capitalismo e monopólio de conhecimento}

O mercado capitalista contemporâneo assenta em estratégias de conhecer e poder que o distinguem profundamente, seja do antigo mercado concorrencial, tendendo à auto-regulamentação, seja do imperialismo, quando a hegemonia se construía com base em posições de força amparadas em políticas do Estado nacional. Se, hoje em dia, a fonte do poder reside no monopólio da invenção científico-tecnológica, é necessário, assim, ir além de uma fenomenologia dos níveis de globalização, tomando em linha de conta o papel determinante do novo capital, na sua diferença específica. Um poder entranhado de saber deve ser combatido por outros poderes capazes de distinguir o que se pode e o que não se pode fazer e conhecer. É esse o desafio de um novo socialismo que abandona a ilusão de ser capaz de criar integralmente uma nova sociedade.

1. João Caraça ${ }^{1}$ desbastou o terreno para esta minha comunicação. Endosso integralmente o que diz a respeito da fusão entre ciência e desenvolvimento tecnológico, principalmente na medida em que este último termina levantando problemas urgentes de caráter eminentemente teórico. Passo adiante e pergunto: se o modo capitalista de produção está visceralmente na dependência do desenvolvimento tecnológico, não passaria também por uma revolução interna radical quando tecnologia se entremeia com ciência? Acredito que sim; essa conivência sui generis entre saber e técnica permite o monopólio da invenção desse novo conhecimento, o que vem a conformar o mercado de forma inédita na história moderna.

Não ignoro que, em geral, as descobertas científicas continuam sendo feitas por pequenos grupos de investigadores trabalhando em rede, mas esse novo conhecimento somente se torna acessível como prática científica depois que enormes investimentos o capacitam a virar um instrumento eletrônico, um remédio, um objeto de entretenimento e assim por diante. Isso abre o caminho para que grandes empresas controlem o movimento do complexo científico-tecnológico, visando assegurar vantagens estraté-

${ }^{1}$ Cf. texto neste mesmo número. 
gicas no mercado. Em poucas palavras: a ciência se subordina ao movimento do capital na medida em que este se torna processo reflexionante inteligente, o que modifica a estrutura concorrencial do mercado capitalista, pois importa a cada empresa, antes de simplesmente obter mais lucro, ocupar posição estratégica diante de aliados e concorrentes, assim como obter conhecimento global do campo de sua atuação.

Ora, se esse novo conhecimento é tanto saber quanto força produtiva, por conseguinte empuxo para universalizar o terreno em que se move cada unidade produtiva, não seria ele responsável pelas novas figuras da globalização? Não teriam elas como condição prévia essa conivência inédita entre saber e capital, cujas forças expansivas se entrelaçam mutuamente? O mercado capitalista contemporâneo é travejado por estratégias de conhecer e poder que o distinguem profundamente seja do antigo mercado concorrencial tendendo à auto-regulamentação, seja daquele vigente durante o imperialismo, quando a hegemonia se construía na base de posições de força amparadas em políticas do Estado nacional.

2. Examinemos com mais vagar o lado formal dessa questão. Há muito tempo venho defendendo a tese de que o Estado, concebido como sistema de ordenamentos jurídicos capaz de julgar conflitos e implementar políticas, depende de um Estado material, ancorado na capacidade, historicamente determinada, de acumular e distribuir fundos públicos. O Estado se apresenta pois, de um lado, como estrutura legal preparada para legislar e se reformar a partir de normas primárias e, de outro, como conjunto de instituições e procedimentos de poder administrado cujo exercício há-de ser financiado publicamente. Para isso carece tanto de impostos como daquele saber que ampara e repõe sua atuação legisladora. Gosto de lembrar que Salomão, ao ser ungido rei, pede a Jeová que lhe dê saber, justamente aquilo que lhe permite, por exemplo, montar um estratagema para conhecer melhor o litígio entre duas mulheres disputando a mesma criança e chegar assim a uma sentença justa. Isso era totalmente impossível numa sociedade primitiva, pois nunca a um chefe cabia a última decisão. Mas esse poder decisório seria inútil se não dispusesse de uma rede de instituições executoras, cuja existência depende de recursos disponíveis. Bem sei que somente as sociedades capitalistas foram capazes de desenhar esse fundo com nitidez. Para avaliar o caminho que foi necessário percorrer para chegar a essa autonomia, convém lembrar a política pré-capitalista do Rei Sol, impossível se não se misturassem fundos privados e fundos públicos. Seja qual for, porém, a estrutura reguladora do Estado, suas leis só podem ser implementadas se no circuito de geração e distribuição da riqueza uma 
parte dela ficar subordinada a uma autoridade suprema. Não é por isso que uma sociedade sem Estado, como aquela dos guaranis, impede esse tipo de acumulação? Em suma, um poder público somente se exerce se puder contar com recursos materiais postos aparentemente a serviço de todos.

Como, porém, se relacionam hoje em dia Estado formal e Estado material? Antes de esboçar uma resposta a essa pergunta é preciso indicar, ainda que brevemente, qual o sentido possível desse relacionamento. Marx distingue em um modo de produção suas formas de representação de seus meios de vir a ser. As categorias das primeiras são repostas por seu próprio movimento. É assim que os produtos entram e saem do sistema formalmente determinados como mercadorias. Mas esse movimento reflexionante não se constituiria se não tivessem fortuitamente se cruzado ao menos dois fatos: acúmulo de dinheiro e mercado de trabalho. Na Europa isso aconteceu somente depois que as cidades voltaram a enriquecer e os servos fugiram dos campos. Em conseqüência, esse evento, embora não esteja ligado à estrutura do capital, à sua lógica interna, não deixa de condicioná-lo historicamente, determinando a maneira pela qual se implanta em certa região. E tal diferença entre condição estrutural e condição histórica não é esquisitice da dialética marxista, pois reaparece mutatis mutandis na filosofia da lógica contemporânea, quando Wittgenstein, por exemplo, distingue no jogo de linguagem o modo de representação, a maneira pela qual os fatos são possivelmente configurados por relações sintáticas a partir de elementos relativamente simples (no jogo de xadrez, os movimentos possíveis do bispo, por exemplo), e os meios de apresentação, as condições materiais e sociais de fato (que conformam um efetivo lance com o bispo). Em suma, os meios de apresentação estipulam condições para efetivar o jogo, construir uma partida. Alguém seria capaz, na Amazônia, de jogar xadrez com peças de gelo? ${ }^{2}$

3. $\mathrm{Na}$ medida em que se pretende conhecer as novas funções do Estado numa economia da informação, mesmo quando se evidenciam seus limites e a necessidade de políticas alternativas, não passa a ser prioritário indagar em que condição o Estado integra a gramática do modo de produção capitalista? Sabemos que a partir do momento em que o capital começa a se mover sozinho - vale dizer, a se repor no próprio nível do funcionamento de novas leis econômicas - cria-se uma sociedade civil burguesa, sintomaticamente chamada por Hegel de "Estado das necessidades e dos carecimentos”, espécie de negativo do Estado como forma do Absoluto. Se o sistema capitalista é aquele em que se produzem mercadorias por meio de merca-

${ }^{2}$ Exploro esse tema em meu livro Apresentação do mundo (Giannotti, 1995). 
dorias, só pode estar estruturalmente desligado dos fundos públicos. Assim, o Estado (formal e material) deixa de alimentar a reposição desse modo de produção para se constituir na qualidade de condição autônoma, isolada de seu movimento de reflexão. Sabemos que o capital, para sobreviver, sempre recorreu ao Estado, mas importa distinguir essa condição histórica de seus condicionamentos estruturais. E se o Estado não é reposto pela lógica interna do capital, só está se exercendo como condição de seu vir-a-ser histórico, meio de apresentação dessa lógica. Se uma sonata para piano somente se apresenta quando tocada por duas mãos, não é por isso que elas fazem parte da obra, cuja beleza aliás não se confunde com a beleza formal da partitura. Mas sem as mãos essa sonata não existe.

Parece-me evidente que as políticas keynesianas recolocam o Estado na reprodução estrutural do capital. De um lado, consolidando o direito do trabalho, o que altera o pressuposto eqüitativo do contrato social e assim por diante; de outro, colocando ao menos uma parte do fundo público ao serviço da reposição do próprio capital, parte que assim se configura como capital estatal. Isso permite que o Estado formal reforce seu papel de identidade imaginária a encobrir conflitos de classe - uma comunidade ilusória (illusorische Gemeinschaftlichkeit), na instrutiva formulação de Marx-, precisamente na medida em que os investimentos estatais reafirmam tanto seu viés classista quanto sua capacidade de conciliar as classes integradas no sistema. Sabemos porém que o Estado keynesiano foi posto em xeque pela crise fiscal, quando os fundos públicos se tornam incapazes de financiar políticas públicas abrangentes por causa do crescimento exponencial dos custos com seguridade, saúde, educação e assim por diante. Depois dessa crise não há como evitar que o Estado proprietário se transforme em Estado regulador, visto que o fundo público se torna insuficiente para assegurar o compromisso de classe diante da ameaça constante de uma população excluída cada vez mais numerosa.

Cabe explicar então como o Estado condiciona a nova economia de informação ao mesmo tempo que é condicionado por ela. Que trama desenham hoje em dia capital e Estado? É de notar que, embora tendo sua autonomia restringida, o Estado-nação, formal e material, não deixa de estar sempre presente na vida cotidiana, na apropriação de uma parte considerável do PIB, por conseguinte no desenvolvimento do próprio capital. Não é o que nos ensina até mesmo a bancarrota de uma nação que afunda conforme segue determinada política econômica? Se, ademais, a Comunidade Européia limita o Estado-nação a ponto de este perder o direito de cunhar moeda, uma nova forma de comunidade não passa a regular a economia da Europa de forma impensável anos atrás? Mas para compreender todos esses fenô- 
menos, desenhar o mapa das determinações recíprocas de instituições que se redefinem no seu processo de reposição e vir-a-ser, convém levar em conta a diferença que se estabelece entre o condicionamento histórico e o estrutural, antes de tudo numa economia de informação, num jogo de linguagem pré-verbal que esconde e ao mesmo revela a regulação estatal de um mercado que se pensa racional.

4. Não me cabe ir além dessas breves formulações lógicas e metodológicas a respeito da difícil questão do condicionamento mútuo entre capital e Estado. Apenas indico uma distinção que julgo importante tanto para que se chegue a uma análise positiva da globalização dos capitais, quanto para determinar a maneira pela qual esta se relaciona com outras formas de globalização. Mais além não me é possível caminhar, não apenas por falta de tempo ou de espaço, mas sobretudo por falta de competência. Como mostram as pesquisas organizadas por Boaventura de Sousa Santos sob o nome de «A Sociedade Portuguesa perante os Desafios da Globalização», a tarefa só pode ser empreendida por uma equipe. Mas se me cabe comentar seus resultados, creio ser conveniente, depois de desfiar os merecidos elogios a todo o grupo, posicionar-me a respeito dos fundamentos lógicos e metodológicos do projeto. Não saberia esconder a boca torcida pelo uso de meu cachimbo. Sabemos desde logo que quanto mais ampla é a obra mais fica na dependência de certos pressupostos. Boaventura de Sousa Santos teve o cuidado de diferenciar níveis em que a globalização se processa:

Distingo quatro processos de globalização produzidos por outros tantos modos de globalização. Eis a minha definição de modo de produção de globalização: é o conjunto de trocas desiguais pelo qual um determinado artefato, condição, entidade ou identidade local estende a sua influência para além das fronteiras nacionais e, ao fazê-lo, desenvolve a capacidade de designar como local outro artefato, condição, entidade ou identidade rival. (Santos, 2001: 69)

Não há dúvida de que a definição descreve com precisão o processo de ir além das fronteiras do Estado-nação, mas de tal modo que o movimento de universalizar cria dialeticamente a localidade antagônica. No fundo de cada processo residiria o mecanismo das trocas desiguais - mas a desigualdade das trocas, abrangendo relações econômicas, culturais, etc., requer que se tenha algum parâmetro para avaliar a igualdade e a desigualdade, e nesse ponto a questão se complica. Se o parâmetro é meramente subjetivo, isto é, faz parte do instrumental teórico do analista, decerto será contestado por outro parâmetro utilizado, com boa ou má-fé, para indicar como a 
desigualdade das trocas resulta de uma situação de crise de paradigmas, embora a longo prazo, descontadas as exceções inevitáveis, seja contrabalançada por uma riqueza que cresce constantemente. Caberia então demonstrar como esse tipo de universalização assenta em mecanismos mais profundos criadores da própria desigualdade, matriz do movimento de universalizar e particularizar. Desse modo, penso que, já no seu início, a análise fenomenológica carece de um complemento ao necessitar legitimar a passagem do universal para o local; somente assim se demonstra que a desigualdade é estrutural e não conjuntural, mero incidente histórico no curso da história. Mas uma análise que aceita essa distinção deixa de ser meramente fenomenológica.

5. A ausência de uma cuidadosa separação entre o histórico e o estrutural conduz ao pecado do anacronismo, pois o tipo fenomenologicamente construído pode ser aplicado sem levar em conta como a reprodução de uma estrutura social define periodizações no curso da história. Essa dificuldade se torna muito evidente nos ensaios publicados no volume Enteados de Galileu? A semiperiferia no sistema mundial da ciência (Nunes e Gonçalves, 2001). Desconfio do emprego indiscriminado do conceito de rede. Não creio que possa abarcar fenômenos tão diferentes como o desenvolvimento das ciências em Portugal, as vicissitudes de Egas Moniz e as estratégias nacionais de autoridade científica. Se hoje em dia a produção do conhecimento depende de esforços de vários grupos distribuídos desigualmente pelo planeta se comunicando online, é porque cada grupo separadamente conta com uma infra-estrutura de tal modo científica e tecnologicamente refinada que se mostra uma verdadeira segunda natureza travada por conhecimentos objetivados. Essa produção simultânea distribuída no espaço nada tem a ver com os processos de influência e redefine a relação tradicional entre centro e periferia precisamente na medida em que está pressupondo a fusão sui generis de ciência e poder. Colocar todos esses diversos fenômenos sob a égide de uma fenomenologia da globalização não suprime suas diferenças históricas? E assim sendo não se impede o conhecimento das novas estruturações por que passa o poder das ciências? No final das contas, não se escondem as tramas do capital contemporâneo?

6. O rico pensamento de Boaventura de Sousa Santos trafega entre cortes radicais e retórica positiva da conciliação. Quando se propõe caracterizar a crise atual como mudança paradigmática das ciências também lida com certa mudança na própria forma da razão. Ao tomar esse caminho tangencia os autores da Escola de Frankfurt. Mas se, para fins heurísticos, tento 
compreender suas teses radicalizando-as, logo me defronto com uma dificuldade. A noção de paradigma, que como todos sabem tem origem na fenomenologia husserliana, funciona no nível das ciências para salientar um núcleo duro de conhecimentos, usualmente aceites e somente refeitos depois de uma crise, distinta daquela outra zona onde se exerce a luta das investigações de ponta. Dessa ótica, fica excluída a possibilidade de se pensar a história das ciências como se elas fossem movidas exclusivamente por uma razão técnica e instrumental, visto que seus pressupostos ontológicos são periodicamente refeitos. A teoria da relatividade, por exemplo, se impõe reformulando categorias básicas, como os conceitos de massa e de tempo, o que altera a própria natureza do fenômeno físico. Uma maneira diferente de individualizar os fenômenos é proposta. Mas quando uma nova forma de ser é deflagrada pela estratégia de compreender dados experimentais que contradizem os princípios mais elementares de uma ciência, não se estão abrindo novos caminhos para que o pensamento se volte para si mesmo, indo portanto muito além da mera razão instrumental? A teoria da relatividade tornou perceptível diferenças e heterogeneidades da percepção do tempo no cotidiano que a física newtoniana tendia a encobrir. E outros exemplos se seguem. Daí minha dificuldade em aceitar uma clivagem rígida entre formas da razão, a não ser que nos deixemos levar pelo historicismo do tipo da lei dos três estados de Comte, ou das idades da razão, de Léon Brunschwig. E não vale simplesmente justapor uma forma a outra sem lidar com seus entrelaçamentos históricos. Mesmo quando a razão é vista como processo objetivo, historicamente dado, de sistematizar fenômenos e ações, não há como evitar, creio eu, confrontar-se com as propostas de regulação e de legitimação já inscritas nos próprios fatos. Uma análise positiva dos processos de racionalização tende a ir além da análise de tudo o que é, pois até o dever se inscreve no horizonte dos fatos.

Bem sei que em seu texto «Os processos da globalização» Boaventura de Sousa Santos (2001) evita essas separações, mas me parece continuar na trilha frankfurtiana ao justapor formas de racionalidade, em particular quando propõe uma sedimentação de planos racionais discursivos para poder avaliá-los no plano da retórica, deixando de levar em conta seus meios de efetuação. Por certo conserva no horizonte tanto a idéia de um sistema mundial, quanto a prevalência do meta-conflito atravessando o pensamento positivo. Mas continua a dar ênfase à justaposição dos processos globalizantes.

A pluralidade de discursos sobre a globalização mostra que é imperioso produzir uma reflexão teórica crítica da globalização e de o fazer de modo a captar a complexidade dos fenómenos que a envolvem e a disparidade dos interesses que neles se 
confrontam. A proposta teórica que apresento aqui parte de três aparentes contradições que, em meu entender, conferem ao período histórico em que nos encontramos a sua especificidade transicional. (Santos: 2001: 60)

São elas: globalização/localização, Estado-nação e não-Estado transnacional e os dois modos de encarar o capitalismo, determinista ou renovador. Se a crise advém da pluralidade de práticas e discursos, cabe então distinguir práticas que se exercem no nível das instituições, das formas de poder, das formas de Direito, atravessadas por um conflito estrutural no quadro de critérios de hierarquização. Mas Boaventura de Sousa Santos também ressalta que essas "aparentes" contradições e todo esse esquema estão sob o fogo cerrado do que ele mesmo chama de "metaconflito": "o conflito sobre os termos do conflito e sobre os critérios que devem definir as hierarquias" (Santos, 2001: 67). No entanto, tão logo essa dualidade passa para a discussão das formas de racionalidade, a solução deixa o campo de batalha da teoria para se deslocar para o plano de uma retórica revalorizada. Para vir a ser emancipador, escreve ele, um discurso científico deve se aproximar do discurso artístico e literário (Santos, 2000: 92). Ora, se não há consenso nem no nível dos resultados analíticos nem na escolha dos critérios, ao menos fica posta a questão: como é possível seguir regras, mesmo aquelas da retórica, sem que se aprenda a manipular os símbolos pelos quais elas se apresentam? Uma coisa é constatar a diafonia dos sistemas teóricos, e outra perguntar se o processamento prático dos conceitos movidos por eles não requer outros condicionamentos que, não se confundindo com a estipulação de princípios teóricos da dedução, laboram o terreno em que se tornam possíveis. Se para pensar é preciso viver e se para viver é preciso comer, a forma da produção da riqueza social continua a nos desafiar prática e teoricamente. Não desenha ela uma espécie de bastidor a partir do qual os conceitos se configuram e adquirem suas respectivas autonomias, um certo horizonte que, embora não constituindo razão de ser, desenha os limites do que se pode ser? Não a teoria econômica, mas o metabolismo que o homem mantém com a natureza, por certo historicamente datado, não configura a mão que toca vida em sociedade? Acredito que estaria mais próximo de Boaventura de Sousa Santos se juntos aprofundássemos sua sugestão de que o discurso emancipador deve se aproximar do discurso artístico e literário. Mas se é para retornar a Kant, vamos até o fim, pois ele nos ensina que um discurso só vem a ser artístico quando se torna um juízo que, em lugar de tratar das determinações do objeto, se volta sobre si mesmo e aprecia a maneira pela qual as representações criam, sem conceitos, parâmetros de 
validade universal, a saber, cria seus parâmetros pré-conceituais ao longo de sua efetuação. Em suma, nossa diferença reside nas formas pelas quais ele pensa, ou não pensa, o problema da reflexão dos fenômenos sociais.

Os problemas filosóficos aparecem, lembra Wittgenstein, quando a linguagem entra em férias. Parece-me que a definição de globalização proposta por Boaventura de Sousa Santos é irrefutável - mas sua fragilidade não advém dessa irrefutabilidade? A meu ver duas coisas se perdem quando Santos se torna discípulo de Santos. A primeira delas, expressa da maneira mais formal, concerne à maneira reflexionante de designar o outro, visto que suas definições operam exclusivamente no nível dos juízos determinantes, vale dizer, que supõem a regra constituída já pressupondo seu bom funcionamento. Nessa dialética, o global se opõe ao local se ambos possuírem diferentes princípios de individuação, e o mesmo acontece com o Estado e assim por diante. Desse ponto de vista, os processos de globalização só podem ser justapostos. O Estado nacional e seu território definem a fronteira entre o mesmo e o outro conforme determinam um outro, mas unicamente por meio de uma reflexão exterior, aquela desenvolvida pelo cientista. Esse predomínio da determinação com a exclusão de processos reflexionantes se mantém nos três níveis. Primeiro, o Estado pode ser desenhado como mesmo para designar outro de igual mesmidade (práticas inter-estatais); segundo, ser atravessado para vir a ser o mesmo e o outro (práticas capitalistas globais); ou, em terceiro lugar, ser simplesmente representado para diferenciar práticas sociais e culturais transnacionais e locais. Parece-me que no fundo dessa tripartição reside uma noção de poder como capacidade de impor trocas desiguais, sendo que a forma desse poder determina um modo de produção de globalização. Mas o que vem a ser troca desigual quando sua medida estrutural e histórica fica na sombra? O que ela pressupõe, como seu meio de apresentação, para sustentar a diferença? Com essa perda do sentido histórico das trocas desiguais não se perderia igualmente a especificidade da globalização contemporânea? Apenas para provocar, poderia dizer que as sociedades tribais se globalizam no plano da difusão cultural, as polei, graças a um sistema de expropriação como aquele instalado pela Confederação de Delos, a Urbs, graças ao controle, tramado por uma burocracia imperial, da distribuição do excedente da riqueza produzida nos grandes latifúndios e assim por diante. Quando os vários processos de globalização são examinados em vista do meta-critério entendido tão-só como força política capaz de desequilibrar as trocas, não se esconde a especificidade dos processos da globalização contemporânea? 
Se não me engano, em vez de voltar às práticas que possam sustentar as desigualdades das trocas em suas especificidades, Boaventura de Sousa Santos toma o caminho inverso, procurando distinguir nelas formas de racionalidade. Mas quando se aproxima da Teoria Crítica encontra, creio eu, dificuldade inversa daquela em que se embrulham os frankfurtianos. Porque constataram que o capital contemporâneo teria perdido aquela regularidade que permitia a Marx pensar a unicidade do sistema capitalista de produção como um todo, transferem a questão da crise do capital para o plano de uma crise da razão. O que passa a importar não é tanto a contradição entre relações sociais de produção e forças produtivas, mas o imperialismo de uma racionalidade tecnológica que perturba o bom funcionamento da boa racionalidade objetiva ou da racionalidade comunicacional. Se Boaventura, levado pelo pós-modernismo, abandona o ideal de qualquer unidade da razão, continua, creio eu, pensando as razões como se fossem sistemas montados sobre opiniões e juízos determinantes (algo define algo exteriormente), sem procurar a reflexão interna desses sistemas, vale dizer, seus processos de individuação. Não há dúvida de que percebe os processos contemporâneos de globalização intimamente ligados a três práticas sociais - inter-estatais, capitalistas globais e socioculturais internacionais a que correspondem respectivamente instituições, formas de poder, formas de direito, conflitos estruturais e critérios de hierarquização. Mas basta percorrer a tábua desses critérios para perceber que as oposições mencionadas - centro, periferia, semiperiferia; global, local - configuram traduções diferentes do problema a ser resolvido. No final das contas, como esses critérios de hierarquização, pautas das práticas desiguais, são repostos por elas? Se há vício em uma medida, qual é o mecanismo específico de sua manutenção?

7. No ponto 3 do seu texto, "A globalização social e as desigualdades", Boaventura de Sousa Santos (2001: 37-42) retoma as teses sobre o pós-imperialismo desenvolvidas por Becker e Sklar, que falam de uma emergente burguesia de executivos, uma nova classe social criando-se a partir das relações entre o setor administrativo do Estado e as grandes empresas privadas ou privatizadas. E formam uma classe «"porque os seus membros, apesar da diversidade de interesses sectoriais, partilham uma situação comum de privilégio sócio-económico e um interesse comum de classe nas relações do poder político e do controlo social que são intrínsecas ao modo de produção capitalista' [Becker e Sklar apud Santos, 2001: 38]. O ramo internacional, a burguesia internacional, é composta pelos gestores das empresas multinacionais e pelos dirigentes das instituições financeiras inter- 
nacionais» (Santos, 2001: 38). E o autor termina o ponto 4, "A globalização política e o Estado-Nação", apoiando-se em formulações de Chase-Dunn et al::

Tal como a classe capitalista está a tentar formar o seu Estado global, de que a Organização Mundial do Comércio é a guarda avançada, as forças socialistas devem criar um "partido mundial" ao serviço de uma "comunidade socialista global" ou "uma comunidade democrática global" baseada na racionalidade colectiva, na liberdade e na igualdade. (Santos, 2001: 50)

Não sei até que ponto vai a adesão de Boaventura de Sousa Santos a essas teses e por isso as comento tal como se fossem apenas endossadas pelos autores citados. Mas ele mesmo explicita que, ao contrário de Marx, não considera o cosmopolitismo e universalidade dos oprimidos como se possuíssem necessariamente uma base classista, operando nesse sentido outras discriminações: sexual, ética, rácica, religiosa, etária, etc. Nisso estamos inteiramente de acordo, mas não acredito que tais diferenças possam se manter isoladas de uma matriz de diferenciação, vale dizer, de algum mecanismo que pressupõe mas também repõe a diferença. No plano econômico não há nada a objetar a essas definições, se por classe nada mais se entende do que um grupo social cujos rendimentos variam dentro de um intervalo definido. É o conceito utilizado, por exemplo, em pesquisas de intenção de voto. Essa classificação, porém, não pretende elucidar o mecanismo da diferenciação. A reflexão é exterior, opera na cabeça dos analistas. Mas é sabido que mesmo uma diferença gritante de rendimentos não desencadeia a luta pela justiça social nem muito menos a luta de classes que possuísse em si mesma a virtude de criar consciência de classe. Não há como negar que os excluídos reclamam de sua situação, mas a partir dessas reclamações não vejo como será possível substituir a lógica da exploração pela lógica da solidariedade. No Brasil escravocrata o primeiro desejo do liberto era comprar um escravo e nos dias de hoje o primeiro desejo de um operário que monta seu próprio negócio é empregar um ajudante. Não há dúvida de que as pessoas apelam para a solidariedade e se organizam em vista dela, mas enquanto essas organizações não colocarem em xeque a raiz da diferenciação não vejo como um movimento social seja capaz de pôr em xeque a sociedade como um todo. $\mathrm{O}$ parâmetro que serve para apontar no enriquecimento das classes médias-altas um vetor para um "partido" mundial, que dialeticamente promoveria o "partido" dos excluídos, vale como qualquer outro argumento retórico, a saber, no plano da convicção e das razões exteriores. O desafio, hoje em dia, é compreender como movimentos sociais se tornam capazes de se exprimir no plano do sistema político. 
O marxismo evitou essa questão na medida em que tais movimentos suprimiriam a política e o Estado, substituindo-os pela organização racional da produção e da sociedade. Essa ilusão foi por água abaixo, nomeadamente porque, estraçalhando-se o vetor que emprestava unidade ao capital social total, por causa da diferenciação estrutural da produtividade do trabalho, não há como imaginar a unicidade do vetor contrário, a unidade do proletariado. O proletariado desapareceu como fato e como conceito. Isso não abole, porém, a tarefa de se buscar as matrizes sociais da diferenciação, assim como os métodos de projeção que as traduzem para o plano político.

É de notar, além do mais, que os executivos e seus aliados não formam uma classe dominante pela simples razão de que no capitalismo contemporâneo as relações de propriedade deixaram de ser diretamente relações sociais de produção. O proprietário de ações pode ser um assalariado, um fundo de pensões ou um empresário schumpeteriano como Bill Gates, mas o comando dos processos produtivos a que essas ações correspondem se dá pela intermediação desses mesmos executivos que, aglutinados em equipes, planejam estrategicamente a continuidade da firma e as condições de seu crescimento. No que poderiam se identificar como classe? Como levar em conta seus interesses a não ser no quadro da concorrência em que estão submersos? Se uma classe se forma quando, para exercer um sistema de regras, passa a defender as regras desse sistema, vale dizer, quando um outro se contrapõe à estrutura normativa que lhe empresta identidade, torna-se impossível considerar os executivos como classe, desprovidos como estão de uma alteridade específica. A afirmação de que a ela, como classe universal, deve se opor à classe universal dos trabalhadores não me parece justificar-se nem no plano teórico nem no plano prático. Se esses executivos defendem interesses de classe e tiram disso proveito, apenas se comportam como os demais aproveitadores, sem que essa situação de privilégio possa identificar-se como a de uma classe oposta àquela das vítimas. A mera oposição entre ricos e pobres não instala classes sociais, vale dizer, um processo de luta que tende a unificar os aliados num movimento social que ponha em xeque a estruturação política existente. O capitalismo contemporâneo, ao separar propriedade privada, de um lado, e comando sobre a produção, de outro, ao clivar os mercados de capital e do trabalho, estraçalha as polaridades das classes. Nesse plano social, "privado" designa apenas o que não é acessível a todos. Daí não se segue todavia que tenha desarmado os mecanismos da dominação, intimamente ligados à necessária ilusão de que uma riqueza social somente se mantém se continuar crescendo, o que arrebanha todos os assalariados na mesma ciranda de um processo social que se coloca como um fim em si mesmo. 
8. Essa crítica à tese de que a matriz da desigualdade se encontra no nível da distribuição dos bens econômicos, socioculturais e até mesmo políticos, sem referência ao modo pelo qual os bens são obtidos e se individualizam, apenas retoma a crítica aos socialistas utópicos. Até que ponto o pensamento dominante da esquerda contemporânea não se alimenta da utopia? No dilema "fatalidade ou utopia" não se esconde uma concepção a-histórica da facticidade? Por isso me aproximo de José Reis quando tenta ir além daquela crítica que se mantém no nível da distribuição dos bens. Até agora não tive acesso a outros de seus escritos, o que me obriga a contentar-me com seu breve ensaio publicado no primeiro volume da coleção «A Sociedade Portuguesa perante os Desafios da Globalização». Ele mostra que a visão corrente da globalização se arma a partir dos seguintes pilares interpretativos: predomínio dos jogos financeiros e bolsistas e do poder de alianças entre as empresas; racionalidade inclusiva total e "apátrida"; absoluta mobilidade dos fatores de produção dominadores; o conhecimento e a informação enquanto apropriações unilaterais dos dominadores; as realidades contextuais vistas como simples produtos derivados e funcionais perante as lógicas inclusivas (Reis, 2001: 119).

Tomando distância das fenomenologias de Boaventura de Sousa Santos, José Reis pretende então "situar-se num plano em que a incerteza e o inesperado englobam uma visão voluntarista sobre a capacidade dos sujeitos, dos processos e dos contextos relacionados para quebrarem os determinismos e o próprio dilema estabelecido pela contraposição entre futuros paradigmáticos e subparadigmáticos”. Assim, por exemplo, ele procura "resolver a dúvida sobre as tensões entre homogeneização e diferenciação optando pela valorização radical dos elementos constitutivos da diferenciação e não os condicionando a dialéticas limitadoras" (Reis, 2001: 110 , nota 1). Aceito essa formulação, mas não as propostas que faz José Reis quando introduz no interior desses elementos constitutivos da diferenciação uma série de limitações à própria racionalidade do processo de globalização econômico. A dificuldade, a meu ver, reside na maneira pela qual cola a esses processos uma diferenciação que não nasce deles mesmos. Não seria mais convincente tentar gerá-los a partir de seu próprio funcionamento? Se as dialéticas limitadoras jogam com reflexos do universal e do particular, não é necessário, para ir até o fundo dos elementos constitutivos do processo de globalização, sair desse reflexo e ir para a reflexão em que o resultado empírico é absorvido no sentido do padrão que as mede? Mais do que de risco, as atuais relações sociais não se apresentam como regularidades que tendem a neutralizar o metro que as torna regulares? 
9. O monopólio da invenção de novos conhecimentos se entrelaça com o processo de enervamento de suas medidas sociais. Um saber somente pode ser monopolizado se uma parte dele for ocultada, impedida de se tornar bem coletivo. Mas desde que esse processo se instale como movimento de identificação de uma sociedade, não há como avaliar como o saber oculto já não perdeu sua vitalidade. Isso se observa quando a difusão dos conceitos científicos ocorre no nível do discurso sem que se propaguem as técnicas correspondentes desses conceitos. Ora, a educação científica implica começar pelo discurso e prolongar-se na prática graças a exercícios e treinamentos para resolver problemas novos. Num de seus aforismos, Wittgenstein nos lembra que na escola as crianças aprendem que a água consiste nos gases hidrogênio e oxigênio, e o açúcar no carbono, hidrogênio e oxigênio. Quem não compreende esses enunciados é estúpido. Mas nesse processo as questões mais relevantes se ocultam, pois falta aos estudantes aquela familiaridade com os conceitos que somente a prática nos laboratórios pode lhes dar.

A questão se complica na medida em que essa distância entre teoria e prática é condição de sua divulgação numa sociedade de massas, o que afeta então particularmente os países periféricos. Não há dúvida de que a possibilidade desse corte nasce com a própria ciência, mas cresce com o alastramento do discurso científico que acompanha o desencantamento do mundo. Não é à toa que Les femmes savantes é praticamente contemporânea ao Discurso do método. Mas nos países periféricos, onde muitos pesquisadores aprendem a falar no registro científico sem terem se apropriado das técnicas correspondentes, como vencer essa distância reforçada pela globalização, a ponto de que a ciência da periferia é muitas vezes tomada pelo centro como mera falação? Não se trata, além do mais, de uma diferença a operar unicamente no nível do discurso, da cultura ou do reconhecimento dos resultados obtidos, mas que atinge a própria maneira de se produzir ciência na periferia. No Brasil não é raro pesquisadores terem notoriedade local sem que sejam reconhecidos no exterior. Em poucos anos suas contribuições estarão esquecidas precisamente porque não foram trabalhadas - quando muito, passam a fazer parte do folclore de nossas universidades. $E$ isso não ocorre porque o centro nos impõe o padrão do que vem a ser ciência, mas simplesmente porque esse discurso, mesmo quando traz conceitos válidos, não se prolonga em práticas produtoras de novos conceitos.

Percebe-se que a fusão da ciência com a tecnologia reforça o espaço do discurso vazio e do fazer-de-conta. A isso se acresce o fantástico aumento do setor dos serviços, onde a medida de sua produtividade é sempre problemática. Como avaliá-la quando se trata de uma consulta médica ou de 
uma aula? Segue-se daí uma osmose terrível entre o fazer e o fazer-de-conta, pois nunca estamos seguros de que o trabalho teórico não se resume num discurso vazio, de que nossas discussões valem apenas como meio de vida, não extravasando os muros das universidades. Visto que esta minha fala também é corroída pelo mesmo defeito, é melhor que me cale.

Mas antes não posso deixar de fazer a última provocação. Muito se discute sobre o socialismo sem que se consiga desenhar para essa palavra um conceito mais ou menos unívoco. Se nasceu ligado a um movimento social que colocava em xeque a propriedade privada, se veio a ser projeto político quando se formulou como promessa de socializar os meios de produção, que sentido ainda poderia manter hoje, quando a questão da propriedade se redefine e se torna secundária diante do crescimento das desigualdades sociais, quando se forma o consenso de que não há no horizonte modo de organizar a produção da riqueza social a não ser deixando que seus fatores assumam a forma mercantil? No entanto, não reside na raiz da desigualdade uma relação de poder que se apropria da invenção do conhecimento, produz benefícios extraordinários que podem até mesmo ser distribuídos àqueles que participam do capital de modo periférico? Mais do que pretender a igualdade, forte na prática mas fracamente na teoria, o socialista não seria aquele que propõe políticas contra esse novo monopólio, que se arma para que o novo conhecimento e seus frutos se tornem acessíveis a todos? O desafio não é apenas a educação universal, que poderia ser inclusive arma de exploração, mas se configura antes de tudo como o arrombamento dos cofres do saber.

\section{Referências Bibliográficas}

Giannotti, José Arthur (1995), Apresentação do mundo. Considerações sobre o pensamento. São Paulo: Companhia das Letras.

Nunes, João Arriscado; Gonçalves, Maria Eduarda (orgs.), Enteados de Galileu? A semiperiferia no sistema mundial da ciência. Porto: Afrontamento.

Reis, José Reis (2001), «A globalização como metáfora da perplexidade? Os processos geo-económicos e o 'simples' funcionamento dos sistemas complexos», in Boaventura de Sousa Santos (org.), Globalização: Fatalidade ou utopia?. Porto: Afrontamento, 109-134.

Santos, Boaventura de Sousa (2000), A crítica da razão indolente. São Paulo: Cortez. Santos, Boaventura de Sousa (2001), «Os processos da globalização», in B. S. S. (org.), Globalização: Fatalidade ou utopia?. Porto: Afrontamento, 31-106. 